\title{
Empirical Works on the Growth Center Concept
}

\author{
Stavros Xiarchos*
}

\section{INTRODUCTION}

Few developments in regional economics have had the impact of the growth pole theory. This has occurred on both a theoretical and a policy level. The basic concept and the policies stemming from it appear, once stated, to be obvious. Theoretically, parts of various growth theories and concepts of regional economics can be fitted into the basic growth pole idea to provide an acceptable explanation of just why a growth center should serve as a fulcrum for the development of a geographic area larger than the space in which it itself is located. ${ }^{1}$ The probable mechanisms of change which occur from the presence of a growth center to induce development of areas peripheral to the center can be derived from these additional theories and explanations of growth. ${ }^{2}$ The literature is filled with the theoretical bases and ramifications of the growth pole theory and, to a lesser extent, with how to identify possible growth centers. However, from the viewpoint of policy, we know little about the most important aspect.

Despite the importance of whether mechanisms actually exist by which positive changes in growth centers have beneficial effects on their regions, few studies have used the existing data in order to assess their existence and strength. It is necessary that they do, in fact, exist and, further, that they be capable of transmitting impulses of sufficient magnitude to bring about the desired changes in their regions. There are several possibilities concerning the existence and strength of these mechanisms: 1. They may exist and be sufficiently strong as to be capable of achieving the desired objectives in the event that sufficient effort is concentrated in the growth center(s). This would be sufficient justification for a growth centers policy. 2. Linkage mechanisms between growth center and periphery may be absent entirely or may be so weak as to have little effect on the peripheral area, or the time lag between investment in the center and the desired result may be unduly long. In these cases serious reconsideration must be given to the use of growth center policy. 3. Linkages of the growth center and its periphery may be stronger with the rest of the world than with each other, in which case policy emphasis must be given to national growth, with special attention to those sectors and/or industries which have the strongest ties with the object areas. 4. It is possible that no indirect mechanisms exist for raising incomes and the standard of life in backward or stagnating areas, and that the appropriate policy would involve transfers, in the form of money or services, to the people living in these areas. This would rule out a growth center policy also. ${ }^{3}$

*Assistant Professor of Economics, Graduate School of Industrial Studies, Thessaloniki, Greece. Dr. Xiarchos holds the Ph.D. from the Pennsylvania State University. His present address is 25 Maurokordatou, Thessaloniki, Greece. 
In the remainder of this paper we will examine briefly, first, the existing empirical studies on growth centers, including the experience of the Economic Development Administration, and second, our own study of growth centers.

\section{EMPIRICAL GROWTH CENTER STUDIES}

Table I sets out a few of the comparable features of previous empirical growth center studies. Although they are few in number, they are varied in approach, areal delineations, method, and variables. However, they all tend to support the general conclusion that growth centers and their peripheral areas do not have linkage mechanisms of sufficient strength and number to justify general use of a growth center policy in the United States.

Nichols, after lengthy discussion as to why growth centers might be expected to have either small or insignificant impacts on their peripheral areas, concludes that the larger urban places of the urban hierarchy of Georgia did serve as growth centers for the state from 1940-1960. ${ }^{4}$ Defects in the empirical analysis, as well as historical data given by Nichols, indicate that the conclusion may be unjustified. The findings of Lewis and Prescott indicate that a growth center strategy may be futile: ${ }^{5}$

Though the growth centers strategy is designed to promote development at this regional level, our analysis indicated that growth patterns within the FEA are not highly complementary with this investment strategy ... The strength of spatial spending patterns from the smallest rural town to the central cities of the FEA suggest that policies promoting centralized urban growth alone will have severe impacts on commercial sales in peripheral communities. Though central city retail and service sales were substantially influenced by income earned in peripheral towns, the effects of increasing demand in the growth centers tend to be spatially self-contained.

Sears and Dymsza, combining the idea of population potential and the gravity concept in order to examine the impact of growth centers on their peripheral areas, find little support for the existence of spread effects. ${ }^{6}$ YuKhin found that some association exists between the rate of growth of income in growth centers and their peripheral areas, but did not go on to explore possible reasons for the association. ${ }^{7}$ Stewart and Benson analyzed growth center-peripheral area relations by means of correlation analysis, regression analysis, and an analysis of migration data, and concluded that "the findings cast doubt on the entire growth center strategy, insofar at least as smaller metropolitan areas are concerned." ${ }^{8}$ The working experience of EDA is in accord with these results: as of the 1972 EDA selfevaluation, 32 completed projects in 12 growth centers had had no appreciable impacts on the areal economies involved, beyond that created directly by the projects. ${ }^{9,10}$

Although the above indicate that growth centers, variously defined, have little impact on their peripheral areas, the idea remains that the growth center strategy is a well-grounded approach to regional policy and 
that the lack of results is due to defects in the models or the data. And, admittedly, there are large problems associated with testing the theory, including the choice of both growth centers and their peripheral areas, lack of agreement as to how to measure the existence of spread effects, the time lags involved, growth transmission mechanisms between center and periphery, and the problem of migration. Alternatively, the absence of spread effects, as suggested by such a variety of centers, peripheral areas, variables, and approaches as are covered by the above studies, may be taken as evidence that the existence of spread effects is extremely doubtful.

\section{A FURTHER GROWTH CENTER TEST}

Our own study (1975) is an improvement over the earlier studies in the following ways: ${ }^{11}$

1. We have not defined growth centers arbitrarily, nor have we chosen any small segment of urban places and called them growth centers to the exclusion of others which are just as likely candidates for the role. The unsatisfactory results of the other empirical studies may possibly have been due either to the exclusion of large segments of the urban system or to the inclusion of all centers of a particular size only. Instead, we have examined as much of the entire existing urban system as possible as growth centers.

The basis of our growth center set is the SMSA centers of the Department of Commerce's Functional Economic Areas (or FEA's) which cover the entire U.S. This set of areas has been delineated by Berry based on the 1960 journey-to-work patterns of the population, on the ideas of central place theory, and on the ideas of innovation theory which is one of the underlying bases of the Perrouxian concept of the growth pole. ${ }^{12}$ Thus based, our study covers nearly the total U.S. geographical area and all growth centers with the exception of those places of under 25,000 population for which it is difficult to obtain data. ${ }^{13}$

2. These same FEA's are the basis of our delineation of peripheral areas. From the total peripheral area of each FEA, as previously delineated by Berry, we have chosen three county samples on the basis of income criteria.

Growth forces from the same growth center may have different effects on various parts of its peripheral area having different prior levels of development. Level of development, we have assumed for the sake of simplicity, will be exhibited in income differences. Accordingly, in order to examine the differential impact of a growth center on parts of its total peripheral area having different levels of development, we have picked three counties from the peripheral area of each FEA: the county with highest per capita income level in 1948; the county with the lowest per capital income level in 1948; and a third county chosen at random. ${ }^{14}$

3 . The growth center concept assumes that the fortunes of the periphery are determined by growth forces from the growth center. Our model treats the peripheral areas as largely passive areas receiving impulses from events in the growth centers. But in recognition that this view oversimplifies reality, we have modified our model to deal with this problem by, 
first, working with areas delineated on the basis of central place theory in which it is assumed that peripheral areas themselves support the growth of their central places, and, second, by working with the three samples outlined in 2. above, which might reasonably be assumed to have different prospects for growth under any set of circumstances common to all peripheral areas of any given growth center. ${ }^{15}$

4. We have included several variables reflecting the economic structure of the growth center. These variables, along with their expected signs, are discussed briefly below.

5. The existing growth center literature suggests that city size has an important impact on the number and magnitude of growth forces transmitted from growth center to its peripheral areas. ${ }^{16}$ In order to test whether the size of growth center has a differential impact, we have divided the growth center set into three groups based on the size of the growth centers, and each of the three samples described in 2 . above has been divided into three groups, depending on the size group to which its growth center belongs. The city size groups are as follows: 54 small cities of 24,000-149,999 population; 61 medium sized cities of 150,000-749,999 population; and 50 large cities of over 750,000 population. The limits of these size groups are arbitrary but have several characteristics which we felt to be desirable: (1) they fit in well with the size ranges defined by other researchers; ${ }^{17}(2)$ there are roughly the same number of cities in each group; and (3) the lower limit of the small city group is defined by the availability of comparable data.

The one appreciable omission from our growth center groups (and also that of Berry) is the set of cities of under 25,000 population. We do not attach great importance to this omission as we expect that we may cautiously infer from the results of the study the probable impact of these smaller places on their peripheral areas.

The impact of growth centers on their peripheral areas has been examined with the following equation: ${ }^{18}$

$$
\begin{aligned}
& \qquad \mathrm{Y}_{\mathrm{P}_{\mathrm{i}}}=\alpha+\mathrm{B}_{1} \mathrm{~F}_{\mathrm{f}_{\mathrm{i}}}+\mathrm{B}_{2} \mathrm{SR}+\mathrm{B}_{3} \mathrm{D}+\mathrm{B}_{4} \mathrm{~N}_{\mathrm{GC}_{\mathrm{i}}}+\mathrm{B}_{5} \mathrm{M}_{\mathrm{GC}_{\mathrm{i}}}+\mathrm{B}_{6} \mathrm{~A}_{\mathrm{GC}_{\mathrm{i}}}+\mathrm{B}_{7} \mathrm{~F}_{\mathrm{GC}_{\mathrm{i}}}+ \\
& \qquad \mathrm{B}_{8} \mathrm{P}_{\mathrm{GC}_{\mathrm{i}}}+\mathrm{B}_{9} \mathrm{Y}_{\mathrm{GC}_{\mathrm{i}}}+\mathrm{B}_{10} \mathrm{NKE}_{\mathrm{GC}_{\mathrm{i}}}+\mathrm{B}_{11} \mathrm{NE}_{\mathrm{GC}_{\mathrm{i}}}+\mathrm{B}_{12} \mathrm{I}_{\mathrm{GC}_{\mathrm{i}}} \\
& \mathrm{i}=1,2, \ldots 165 \\
& \text { where } \mathrm{P}_{\mathrm{i}}=\text { county in the peripheral area of FEA }
\end{aligned}
$$

$$
\begin{aligned}
G_{i}= & \text { the growth center of } F E A_{i} . \\
f_{i}= & F A_{i} . \\
Y_{P_{i}}= & \text { the rate of change of per capita income in the ith county from } \\
& 1960-1970 . \text { Although many possible indicators of welfare exist, } \\
& \text { per capita income is the most inclusive single indicator. Its well } \\
& \text { known disadvantages are more than offset by its advantages and } \\
& \text { ready availability. } \\
F_{f_{i}}= & \text { a dummy variable indicating whether the FEA has multiple } \\
& \text { growth centers (as do } 2 / 5) \text {. Differences among FEA's due to } \\
& \text { having more than one growth center should be indicated by this } \\
& \text { variable. }
\end{aligned}
$$


$\mathrm{SR}=$ the size of the ith county relative to its respective GC in 1960, as measured by populations. The potential impact of a GC on its peripheral area may be summed up in the relative sizes of the two areas. We expect that the larger the GC relative to the county, the lower the value of the coefficient will be.

$\mathrm{D}=$ the distance separating the chief urban place of county i from its GC. The strength of spread effects from a GC should, logically, decrease as the distance between center and peripheral area increase, so a negative sign is expected.

$\mathrm{N}_{\mathrm{GC}_{\mathrm{i}}}=$ the rate of change in employment in $\mathrm{GC}_{\mathrm{i}}, 1960-1970$. The creation of new employment opportunities in the center may lead to increased peripheral area incomes, either directly, as these jobs are filled by peripheral area residents, or indirectly, through the working of the multiplier or the creation of new inter-industry linkages. We expect to obtain a positive sign for the coefficient.

$\mathrm{M}_{\mathrm{GC}_{\mathrm{i}}}=$ the net migration rate for $\mathrm{GC}_{\mathrm{i}}, 1960-1970$. We expect a positive association with $\mathrm{Y}_{\mathrm{Pi}}$, based on the assumption that migrants from peripheral areas are more attracted to their own growth center SMSA's than to those outside their own FEA. Also, a positive net migration rate is likely to indicate that economic growth is occurring in the center.

$\mathrm{A}_{\mathrm{GC}_{\mathrm{i}}}=$ the age of $\mathrm{GC}_{\mathrm{i}}$, in decades. Increasing age in a center brings two sets of forces which counter each other: on the one hand, increasing linkages, intercommunication and integration which should foster continued growth and, on the other hand, dated public and private capital, which may retard future growth. We tentatively expect that the former will offset the latter, and that the association between $\mathrm{Y}_{\mathrm{Pi}}$ and $\mathrm{A}$ will be positive.

$\mathrm{E}_{\mathrm{GC}_{\mathrm{i}}}=$ the median number of school years completed by the over age 25 population as of 1970. The higher the level of education attained by the residents of the GC, the higher the level of skill and technology in the center, and the greater the spread effects from the center may be expected to be. A positive sign is expected for the coefficient.

$\mathrm{P}_{\mathrm{GC}_{\mathrm{i}}}=$ the percentage of the population of $\mathrm{GC}_{\mathrm{i}}$ which had income of $\$ 3,000$ or less. This variable is a proxy for the income distribution of the growth center. We assume that the larger is $\mathrm{P}_{\mathrm{GCi}}$, the less equal the distribution of incomes in the center. A skewed distribution may indicate long term structural problems, aggravated by a consequent low level of aggregate demand in the center. It may also indicate a large, under used pool of labor to which new jobs might be offered prior to peripheral area residents. In either case, spillover effects from growth centers might be quite small. On the other hand, centers experiencing growth of a type or magnitude sufficient to cause spillover effects may 
experience rapid immigration leading to an increase in the low income group, at least temporarily. In this event, a positive association may be expected between $\mathrm{Y}_{\mathrm{pi}}$ and $\mathrm{P}_{\mathrm{GCi}}$. We expect that the sign will be positive.

$\mathrm{Y}_{\mathrm{GC}_{\mathrm{i}}}=$ the rate of change of per capita income in the ith GC, 1960-1970. We expect a positive association between this variable and the dependent variable, based on the entire growth pole rationale.

$\mathrm{NKE}_{\mathrm{GC}_{\mathrm{i}}}=$ new capital expenditures made in manufacturing in $\mathrm{GC}_{\mathrm{i}}$ in 1958 , in thousands of dollars. We expect that capital investment should be a positive function of the growth of a center and, through spillover effects, positively related to income growth in peripheral areas.

$\mathrm{NE}_{\mathrm{GC}_{i}}=$ the rate of change in the number of new manufacturing establishments in $\mathrm{GC}_{\mathrm{i}}, 1960$-1970. This variable indicates growth in the center and, in turn, may serve as a basis for further growth in both center and periphery by way of income and inter-industry multipliers. We expect a positive sign for the coefficient.

$\mathrm{I}_{\mathrm{GC}_{\mathrm{i}}}=$ an index of industrial structure in $\mathrm{GC}_{\mathrm{i}}$ in 1960 , based on the Ullman-Dacey minimum requirements technique. ${ }^{19}$ Specialized centers, indicated by high index values, may have greater interindustry linkages with their peripheral areas but may also subject these peripheral areas to large swings in employment due to cyclical changes in demand. Diversified centers are more likely to provide more steady employment and income for themselves and for their peripheral areas.

The use of time lags for the variables presented a problem. The exact lag used for each was dictated partly by plausibility, and partly by the availability of data. This may be considered as a defect. However, our lack of knowledge on this important aspect of the growth pole concept at present means that there is no a priori basis for choosing time lags; hence, those used here may be as good as any other choices.

\section{Results of the Model}

The results are presented in the accompanying tables (II, III, and IV) which sum up the analysis for low income, high income, and randomly selected counties, respectively, by total sample and by city size category. $\overline{\mathrm{R}}^{2} \mathrm{~s}$ for the three county groups are .055 (low income), .686 (high income), and .4 (random); for this set of growth centers and their peripheral areas, the combined impact of the independent variables is greater the higher the prior income level of the peripheral area. This indicates that the prior development level of the peripheral areas, as summed up in the income level, plays a role in determining the impact of growth forces transmitted by a growth center. We may infer from this that if growth forces are transmitted from a growth center, the resultant growth in the total peripheral area of the center will still be geographically unbalanced, given the 
(commonly found) existence of prior intra-areal imbalance. Although the problem may be obscured by alternative areal delineations, it will not disappear by growth center strategy. In addition, our results indicate an extremely small impact on the lowest income areas, those which correspond most closely to the set of peripheral areas which are the focus of regional policy objectives.

Regressions for each of these county groups by city size category indicate that city size is an important consideration in growth center strategy. The tables show that the greatest impact is made by medium sized cities in the cases of low and high income county groups and by large sized cities for randomly selected counties. Two results stand out: 1 . the small sized city as growth center has little impact in any of the three samples; and 2. the small sized city has the least impact on its periphery when that periphery is in the low income county group. This latter combination, small city and low income peripheral area, corresponds most closely to those of EDA; EDA growth centers tend to be toward the lower end of our small city size range or are even smaller cities chosen primarily because of their existence within the object areas. Although we cannot be certain of the impact of these very small growth centers without testing data from these centers, we might reasonably expect, based on our results and those of the other studies we have mentioned, that their impact might be even smaller than that of our small city group.

A very brief discussion of possible explanations for the relatively large growth center impacts from our medium sized city groups may serve also to illustrate the defects of small cities as possible growth centers. Cities in the intermediate size range, in general, provide, on the one hand, significant agglomeration economies, scale economics in the provision of public and private services, a varied labor supply, and reasonable sized markets for the outputs of basic and residentiary sectors, and on the other hand, a relative freedom from the negative externalities of very large cities. This position may indicate that they may be stimulated to some degree of further growth without the onset of negative externalities, if that growth is planned and guided. Although small cities lack the negative externalities of large sized cities also, they lack all or most of the attractive characteristics of medium sized and large cities associated with economies of scale.

\section{Conclusions}

The few empirical growth center studies suggest, in general, that growth centers have little of the economic impact on their peripheral areas which is posited by the growth pole theory and its implications and extensions. The practical evidence from the EDA supports this same conclusion. The results of our study point in the same direction; they indicate that the presence of a growth center does not ensure that spread effects will be transmitted to its peripheral areas. Two things must be taken into consideration in planning a growth center approach in addition to those usually stressed: the size of the growth center and the potential of the peripheral area. In general, medium sized cities (population range from 250,000- 
$750,000)$ have the greatest income impact on their peripheral areas, no matter what the potential of the peripheral area. And low income areas have the lowest potential for receiving growth impulses from growth centers of any size, but especially from small city growth centers. This indicates that in areas of greatest concern, low income, low potential areas with few or no urban places outside of the small city category, a growth center strategy may be futile.

We have had little success in uncovering the avenues by which growth forces in centers are transmitted into peripheral areas. Various avenues cited in growth center literature such as migration, increased employment in growth centers, new capital investment in growth centers, are not statistically significant in explaining the rate of change of per capita income in areas peripheral to growth centers. Instead, our results indicate that it may be more general measures aimed at upgrading the education and skills and the standard of life in centers which are more important in explaining the variation in the rate of change of peripheral area income than more rigidly conceived economic variables. If extended and repeated tests bear out the results of this study, investment in social and human capital, possibly along with an increase in direct transfer payments, may be "better" in terms of the fulfillment of our objectives for poorer areas of the U.S. than a growth center strategy.

\section{FOOTNOTES}

${ }^{1}$ We will not burden or bore the reader with explanations of the transition from growth pole to growth center. If explanation is desired, see 2, below.

${ }^{2}$ See F. Perroux, "Economic Space: Theory and Applications," Vol. 64 Quarterly Journal of Economics (Feb. 1950); D. Darwent, "Growth Poles and Growth Centers in Regional Planning-A Review," Environment and Planning, Vol. III (1969), pp. 5-31; Tormod Hermansen, "Development Poles and Development Centers in National and Regional Development," pp. 1-64 in Antoni Kuklinski, ed., Growth Poles and Growth Centers in Regional Planning. (The Hague: Mouton and Company, 1972).

${ }^{3}$ There are several rationales for the use of a growth center strategy, of which the harnessing of spread effects is only one. However, the argument from spread effects is the strongest, the one most often used to explain the desired results (See EDA writings), and the chief reason for the policy application; if the phenomenon does not occur, the basic foundation for this policy is destroyed. Other uses may then still exist which would make a growth centers policy reasonable. These include $1 /$ offering alternative migration centers, other than large cities, to the inhabitants of poor rural areas who would like to move from those areas, $2 /$ providing a more adequate level of educational, health, and social services to poor rural areas than can be supported by the resources of these areas, and 3/a Hawthorne-type effect by which the inhabitants of the areas may create for themselves an environment more conducive to growth. It may, however, be cheaper and more expedient to provide these types of benefits through some such avenue as income transfers rather than the more indirect method of working through growth centers. A "growth centers" policy has a somewhat hollow ring if the centers have no potential for the transmission of growth.

${ }^{4}$ Vida Nichols, "Growth Poles: An Evaluation of Their Propulsive Effect," Environment and Planning, Vol. I (1969), pp. 193-208: also, Vida Nichols, Growth Poles: An
Investigation of Their Potential for Regional Development. RSRI Discussion Paper Series, No. 30 (Phila.: May, 1969).

${ }^{5}$ William C. Lewis and James R. Prescott, "UrbanRegional Development and Growth Centers: An Econometric Study," Journal of Regional Science, Vol. 12, No. 1 (1972), pp. 57-70. Quotation pp, 68-9

${ }^{6}$ David W. Sears and Richard B. Dymsza, Growth Pole Theory: A Test. Paper, Department of Agricultural Economics, Cornell University (Ithaca, New York: 1969).

${ }^{7}$ Richard YuKhin, Study reported in Niles Hansen, Location Preferences, Migration, and Regional Growth: A Study of the South and Southwestern United States. (New York: Praeger Publishers, 1973).

${ }^{8}$ Charles T. Stewart and Virginia B. Benson, Linkages Between Small Metropolitan Areas and Their Hinterlands With Implications for Regional Development Policies. Paper prepared under the EDA. (Washington, D.C.: The George Washington University, May, 1972). Quotation, p. 16.

${ }^{9}$ U.S. Department of Commerce, Economic Development Administration, Program Evaluation: The Economic Development Administration Growth Center Strategy. (Washington: Feb., 1972), pp. 13-20.

${ }^{10} \mathrm{However}$, in view of the multiplicity of objectives of the EDA, we cannot say, based on the economic evaluation alone, that the projects were failures.

${ }^{11}$ Stavros Xiarchos, Growth Centers and Their Spheres of Influence. Unpublished Ph.D. Dissertation. (the Pennsylvania State University, 1976).

${ }^{12}$ See various works of Brian Berry, including: Growth Centers in the American Urban System. Vols. I and II. (Cambridge, Mass.: Ballenger Publishing Company, 1973); "Commuting Patterns, Labor Market Participation, and Regional Potential," Growth and Change, Vol. I (1970), pp. 3-10; and "Hierarchical Diffusion: The Basis of Development Filtering and Spread in a system of Growth Centers," pp. 108-138 in Niles Hansen, ed., Growth Cen- 
ters in Regional Economic Development. (New York: Free Press, 1972).

${ }^{13}$ Of 171 FEA's, 165 were retained for the study. The others, Alaska and Hawaii and 4 smaller FEA's were omitted due to lack of comparable data for 1960 and 1970.

${ }^{14}$ We have chosen the year 1948 in choosing our samples based on county potential since we have assumed that the boom accompanying and following the war years would have brought out the potential of these places for development. We have not, however, attempted to verify this assumption.

${ }^{15}$ It might be argued that a more appropriate approach would have been a simultaneous equation model. However, at this point we know very little about the relationships between growth center and peripheral area, definitely not enough to model a simultaneous equation system. Our model should catch the total effect of a number of inter-relationships and indirect impacts.

${ }^{10}$ See Harry Richardson, Regional Economics: Location Theory, Urban Structure, and Regional Change. (New York: Praeger Publishers, 1969), pp. 415-428.

${ }^{17}$ See Niles Hansen, Intermediate Sized Cities as Growth
Centers: Applications for Kentucky, the Piedmont Crescent, the Ozarks, and Texas. (New York: Praeger Publishers, 1971).

${ }^{18}$ Data used in testing the equation are from various issues of the County City Data Book ( $\mathrm{Y}_{\mathrm{Pl}}, \mathrm{SR}, \mathrm{N}_{\mathrm{GCl}}, \mathrm{M}_{\mathrm{GCl}}$ $\mathrm{E}_{\mathrm{GCl}}, \mathrm{P}_{\mathrm{GCi}}, \mathrm{Y}_{\mathrm{GCl}}, \mathrm{NKE}_{\mathrm{GCl}}, \mathrm{NE}_{\mathrm{GCl}}$; Berry's Growth Centers .... $\left(\mathrm{F}_{\mathrm{n}}\right)$; various issues of the decennial Census of the Population $\left(\mathrm{A}_{\mathrm{GCl}}, \mathrm{I}_{\mathrm{GCl}}\right)$; Ullman, Dacey, and Brodsky, The Economic Base of American Cities ... $\left(\mathrm{I}_{\mathrm{GC} 1}\right)$; and (D) U.S. outline map \#3078 and the 1974 Rand McNally Commercial Atlas and Marketing Guide.

${ }^{19}$ See F. L. Ullman and M. F. Dacey, "The Minimum Requirements Approach to the Urban Economic Base," Papers and Proceedings of the Regional Science Association, Vol. 6 (1960), pp. 175-194; F. L. Ullman, M. F. Dacey, and Harold Brodsky, The Economic Base of American Cities. Profiles for the 101 Metropolitan Areas Over 250,000 Population Based on Minimum Requirements for 1960. Center for Urban Research and Development, Monograph \#1. (Seattle: University of Washington, 1969); Roy W. Bahl, Robert Firestine, and Donald Phares, "Industrial Diversity in Urban Areas: Alternative Measures and Intermetropolitan Comparisons, ${ }^{n}$ Economic Geography, Vol. 47 (July, 1971), pp. 414-425.

\section{REFERENCES}

Bahl, Roy W., Robert Firestine, and Donald Phares, "Industrial Diversity in Urban Areas: Alternative Measures and Intermetropolitan Comparisons," Economic Geography, Vol. 47 (July, 1971), pp. 414-425.

Berry, Brian, "Commuting Patterns, Labor Market Participation, and Regional Potential," Growth and Change, Vol. I (1970), pp. 3-10.

, Growth Centers in the American Urban System. Vols. I and II. (Cambridge, Mass.: Ballenger Publishing Company, 1973).

, "Hierarchical Diffusion: the Basis of Developmental Filtering and Spread in a System of Growth Centers," pp. 108-138 in Niles Hansen, ed., Growth Centers in Regional Economic Development. (New York: Free Press, 1972).

Darwent, David F., "Growth Poles and Growth Centers in Regional Planning-A Review," Environment and Planning, Vol. III (1969).

Hansen, Niles, Growth Centers in Regional Economic Development. (New York: Free Press, 1972).

Intermediate Sized Cities as Growth Centers: Applications for Kentucky, The Piedmont Crescent, the Ozarks, and Texas. (New York: Praeger Publishers, 1971).

, Location Preferences, Migration, and Regional Growth: A Study of the South and Southwest United States. (New York: Praeger Publishers, 1973).

Hermansen, Tormod, "Development Poles and Development Centers in National and Regional Development," pp. 1-64 in Antoni Kuklinski, ed., Growth Poles and Grwoth Centers in Regional Planning. (The Hague: Mouton and Company, 1972).

Kuklinski, Antoni, ed., Growth Poles and Growth Centers in Regional Planning. (The Hague: Mouton and Company, 1972).

Lewis, William C., and James R. Prescott, "UrbanRegional Development and Growth Centers: an Econometric Study," Journal of Regional \&cience, Vol. 12 (1972), pp. 57-70.
Nichols, Vida, "Growth Poles: An Evaluation of Their Propulsive Effect," Environment and Planning, Vol. I (1969), pp. 193-208.

, Growth Poles: An Investigation of Their Potential for Regional Development. RSRI Discussion Paper Series, No. 30 (Phila.: May, 1969).

Perroux, Francois, "Economic Space: Theory and Applications," Quarterly Journal of Economics, Vol. 64 (Feb., 1950).

Richardson, Harry W., Regional Economics: Location Theory, Urban Structure, and Regional Change. (New York: Praeger Publishers, 1969).

Sears, David W., and Richard B. Dymsza, Growth Pole Theory: A Test. Paper, Department of Agricultural Economics, Cornell University (Ithaca, New York: 1969).

Stewart, Charles T., and Virginia Benson, Linkages Between Small Metropolitan Areas and Their Hinterlands with Implications for Regional Development Policies. Paper prepared under EDA. (Washington, D.C.: The George Washington University, May, 1972).

Ullman, F. L., and M. F. Dacey, "The Minimum Requirements Approach to the Urban Economic Base," Papers and Proceedings of the Regional Science Association, Vol. 6 (1960), pp. 175-194.

and Harold Brodsky, The Economic Base of American Cities. Profiles for the 101 Metropolitan Areas over 250,000 Population Based on Minimum Requirements for 1960. Center for Urban Research and Development, Monograph \#1 (Seattle: University of Washington, 1969).

United States Department of Commerce, The Economic Development Administration, Program Evaluation: The Economic Development Administration Growth Center Strategy. (Washington: Feb., 1972).

Xiarchos, Stavros, Growth Centers and Their Spheres of Influence. Unpublished Ph.D. Dissertation. (The Pennsylvania State University, 1976).

YuKhin, Richard, as reported in Niles Hansen, ed., Location Preferences, Migration, and Regional Growth: A Study of The South and Southwest Uniled States. (New York: Praeger Publishers, 1973). 
TABLE I

EMPIRICAL STUDIES ON GROWTH POLES

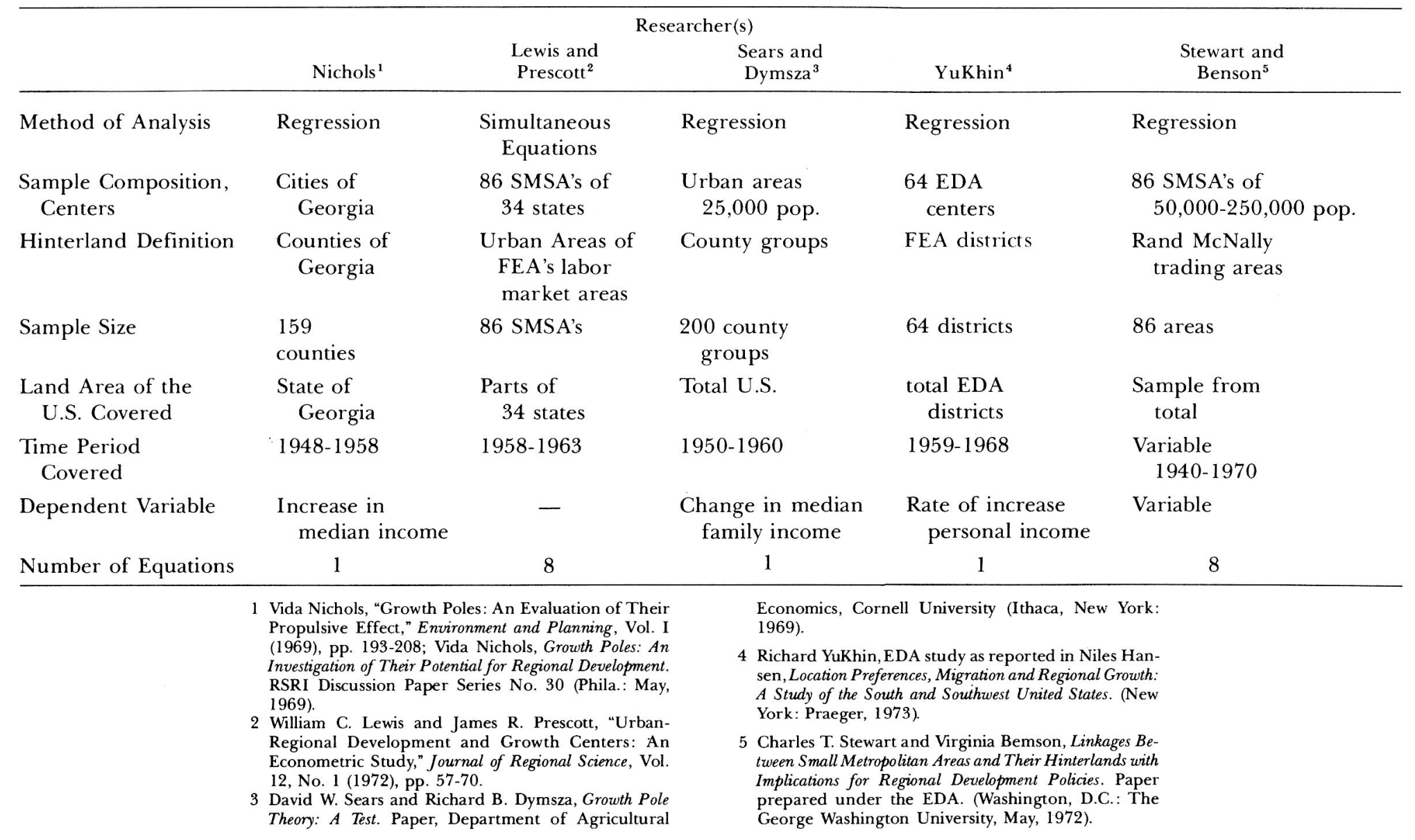


TABLE II

Regression Coefficients for the Low Income County Sample

\begin{tabular}{|c|c|c|c|c|}
\hline \multirow[b]{2}{*}{ Variable } & \multicolumn{4}{|c|}{ Regression } \\
\hline & Total & Small City & Medium City & Large City \\
\hline$\alpha$ & $\begin{array}{c}3.591 \\
(4.239)^{\mathrm{a}}\end{array}$ & $\begin{array}{c}1.493 \\
(1.719)^{\mathrm{a}}\end{array}$ & $\begin{array}{c}0.468 \\
(0.591)\end{array}$ & $\begin{array}{l}7.382 \\
(2.172)^{\mathrm{a}}\end{array}$ \\
\hline$F_{\text {fi }}$ & $\begin{array}{l}-0.038 \\
(0.373)\end{array}$ & $\begin{array}{c}0.079 \\
(0.695)\end{array}$ & $\begin{array}{c}0.053 \\
(0.728)\end{array}$ & $\begin{array}{l}-0.242 \\
(0.671)\end{array}$ \\
\hline SR & $\begin{array}{l}-0.125 \\
(0.483)\end{array}$ & $\begin{array}{l}-0.075 \\
(0.442)\end{array}$ & $\begin{array}{l}-0.804 \\
(1.376)^{\mathrm{a}}\end{array}$ & $\begin{array}{l}-0.151 \\
(0.131)\end{array}$ \\
\hline $\mathrm{D}$ & $\begin{array}{l}-0.00015 \\
(0.769)\end{array}$ & $\begin{array}{l}-0.005 \\
(1.745)^{\mathrm{a}}\end{array}$ & $\begin{array}{l}-0.00013 \\
(1.498)^{\mathrm{a}}\end{array}$ & $\begin{array}{l}-0.009 \\
(0.723)\end{array}$ \\
\hline $\mathrm{N}_{\mathrm{GC}}$ & $\begin{array}{c}0.059 \\
(0.278)\end{array}$ & $\begin{array}{l}-0.155 \\
(0.906)\end{array}$ & $\begin{array}{l}-0.123 \\
(0.638)\end{array}$ & $\begin{array}{l}-0.327 \\
(0.221)\end{array}$ \\
\hline $\mathrm{M}_{\mathrm{GC}}$ & $\begin{array}{c}0.136 \\
(0.284)\end{array}$ & $\begin{array}{c}-0.686 \\
(0.179)\end{array}$ & $\begin{array}{c}0.183 \\
(0.535)\end{array}$ & $\begin{array}{c}1.562 \\
(0.679)\end{array}$ \\
\hline $\mathrm{A}_{\mathrm{GC}}$ & $\begin{array}{c}0.003 \\
(1.754)^{\mathrm{b}}\end{array}$ & $\begin{array}{l}-0.003 \\
(0.719)\end{array}$ & $\begin{array}{c}0.003 \\
(1.418)\end{array}$ & $\begin{array}{c}0.007 \\
(0.936)\end{array}$ \\
\hline $\mathrm{E}_{\mathrm{GC}}$ & $\begin{array}{l}-0.208 \\
(3.093)^{\mathrm{a}}\end{array}$ & $\begin{array}{l}-0.056 \\
(0.859)\end{array}$ & $\begin{array}{l}-0.054 \\
(0.621)\end{array}$ & $\begin{array}{l}-0.483 \\
(1.882)^{\mathrm{a}}\end{array}$ \\
\hline $\mathbf{P}_{\mathrm{GC}}$ & $\begin{array}{l}-0.197 \\
(1.566)^{\mathrm{a}}\end{array}$ & $\begin{array}{l}-0.162 \\
(1.464)^{\mathrm{a}}\end{array}$ & $\begin{array}{c}1.388 \\
(1.830)^{\mathrm{a}}\end{array}$ & $\begin{array}{l}-0.121 \\
(0.089)\end{array}$ \\
\hline $\mathrm{Y}_{\mathrm{GC}}$ & $\begin{array}{l}-0.205 \\
(0.956)\end{array}$ & $\begin{array}{c}0.393 \\
(1.146)\end{array}$ & $\begin{array}{l}0.869 \\
(2.598)^{\mathrm{a}}\end{array}$ & $\begin{array}{l}-1.087 \\
(0.741)\end{array}$ \\
\hline $\mathrm{NKE}_{\mathrm{GC}}$ & $\begin{array}{l}-0.0000002 \\
(0.385)\end{array}$ & $\begin{array}{l}-0.000005 \\
(0.467)\end{array}$ & $\begin{array}{l}-0.000002 \\
(1.259)^{\mathrm{a}}\end{array}$ & $\begin{array}{l}-0.0000003 \\
(1.128)\end{array}$ \\
\hline $\mathrm{NE}_{\mathrm{GC}}$ & $\begin{array}{c}0.074 \\
(0.237)\end{array}$ & $\begin{array}{c}0.393 \\
(1.146)\end{array}$ & $\begin{array}{c}0.365 \\
(1.331)^{\mathrm{a}}\end{array}$ & $\begin{array}{c}0.747 \\
(0.442)\end{array}$ \\
\hline $\mathbf{I}_{\mathrm{GC}}$ & $\begin{array}{l}-0.052 \\
(2.851)^{\mathrm{b}}\end{array}$ & $\begin{array}{c}0.008 \\
(0.634)\end{array}$ & $\begin{array}{c}0.033 \\
(2.529)^{\mathrm{b}}\end{array}$ & $\begin{array}{l}-0.091 \\
(1.439)\end{array}$ \\
\hline$\overline{\mathrm{R}}^{2}$ & .055 & .086 & .408 & .033 \\
\hline F & 1.81 & 1.42 & 4.45 & 0.867 \\
\hline S.E.E. & 0.618 & 0.348 & 0.257 & 1.052 \\
\hline
\end{tabular}


TABLE III

Regression Coefficients for the High Income County Sample

\begin{tabular}{|c|c|c|c|c|}
\hline \multirow[b]{2}{*}{ Variable } & \multicolumn{4}{|c|}{ Regression } \\
\hline & Total & Small City & Medium City & Large City \\
\hline$\alpha$ & $\begin{array}{l}2.277 \\
(5.667)^{\mathrm{a}}\end{array}$ & $\begin{array}{c}0.339 \\
(0.812)\end{array}$ & $\begin{array}{l}2.573 \\
(2.649)^{\mathrm{a}}\end{array}$ & $\begin{array}{l}2.736 \\
(2.307)^{\mathrm{a}}\end{array}$ \\
\hline$F_{\text {fi }}$ & $\begin{array}{c}0.046 \\
(0.625)\end{array}$ & $\begin{array}{c}0.066 \\
(0.612)\end{array}$ & $\begin{array}{c}0.011 \\
(0.059)\end{array}$ & $\begin{array}{l}-0.026 \\
(0.575)\end{array}$ \\
\hline SR & $\begin{array}{l}0.289 \\
(6.119)^{\mathrm{a}}\end{array}$ & $\begin{array}{l}-0.124 \\
(1.692)^{\mathrm{a}}\end{array}$ & $\begin{array}{l}0.456 \\
(5.044)^{\mathrm{a}}\end{array}$ & $\begin{array}{l}-0.129 \\
(1.455)^{\mathrm{a}}\end{array}$ \\
\hline $\mathrm{D}$ & $\begin{array}{l}0.004 \\
(1.913)^{\mathrm{a}}\end{array}$ & $\begin{array}{l}-0.043 \\
(2.151)^{\mathrm{a}}\end{array}$ & $\begin{array}{c}0.011 \\
(2.055)^{\mathrm{a}}\end{array}$ & $\begin{array}{l}-0.001 \\
(0.317)\end{array}$ \\
\hline $\mathrm{N}_{\mathrm{GC}}$ & $\begin{array}{l}-0.037 \\
(0.260)\end{array}$ & $\begin{array}{l}-0.061 \\
(0.312)\end{array}$ & $\begin{array}{c}0.231 \\
(0.543)\end{array}$ & $\begin{array}{l}-0.202 \\
(1.088)\end{array}$ \\
\hline $\mathrm{M}_{\mathrm{GC}}$ & $\begin{array}{l}-0.041 \\
(0.452)\end{array}$ & $\begin{array}{c}0.211 \\
(0.998)\end{array}$ & $\begin{array}{l}-0.158 \\
(0.967)\end{array}$ & $\begin{array}{l}-0.239 \\
(0.789)\end{array}$ \\
\hline $\mathrm{A}_{\mathrm{GC}}$ & $\begin{array}{c}0.002 \\
(5.887)^{\mathrm{b}}\end{array}$ & $\begin{array}{c}0.002 \\
(1.625)\end{array}$ & $\begin{array}{l}0.002 \\
(3.485)^{\mathrm{b}}\end{array}$ & $\begin{array}{l}-0.003 \\
(0.034)\end{array}$ \\
\hline $\mathrm{E}_{\mathrm{GC}}$ & $\begin{array}{l}-0.154 \\
(4.521)^{\mathrm{a}}\end{array}$ & $\begin{array}{c}0.038 \\
(0.913)\end{array}$ & $\begin{array}{l}-0.193 \\
(2.348)^{\mathrm{a}}\end{array}$ & $\begin{array}{l}-0.038 \\
(1.146)\end{array}$ \\
\hline $\mathrm{P}_{\mathrm{GC}}$ & $\begin{array}{l}-0.289 \\
(5.834)^{\mathrm{a}}\end{array}$ & $\begin{array}{l}-0.097 \\
(1.753)^{\mathrm{a}}\end{array}$ & $\begin{array}{l}-0.426 \\
(4.955)^{\mathrm{a}}\end{array}$ & $\begin{array}{c}0.030 \\
(0.175)\end{array}$ \\
\hline $\mathrm{Y}_{\mathrm{GC}}$ & $\begin{array}{l}-0.078 \\
(1.103)\end{array}$ & $\begin{array}{l}0.254 \\
(2.146)^{\mathrm{a}}\end{array}$ & $\begin{array}{l}-0.204 \\
(1.608)^{\mathrm{a}}\end{array}$ & $\begin{array}{l}-0.060 \\
(0.319)\end{array}$ \\
\hline $\mathrm{NKE}_{\mathrm{GC}}$ & $\begin{array}{l}-0.00000004 \\
(0.466)\end{array}$ & $\begin{array}{r}-0.00002 \\
(3.010)^{\mathrm{a}}\end{array}$ & $\begin{array}{l}0.0000001 \\
(0.297)\end{array}$ & $\begin{array}{l}0.00000001 \\
(0.208)\end{array}$ \\
\hline $\mathrm{NE}_{\mathrm{GC}}$ & $\begin{array}{l}0.247 \\
(1.114)\end{array}$ & $\begin{array}{l}0.096 \\
(1.011)\end{array}$ & $\begin{array}{l}0.132 \\
(0.211)\end{array}$ & $\begin{array}{c}0.193 \\
(0.898)\end{array}$ \\
\hline$I_{G C}$ & $\begin{array}{l}-0.014 \\
(1.098)\end{array}$ & $\begin{array}{l}-0.002 \\
(1.321)\end{array}$ & $\begin{array}{l}-0.006 \\
(0.231)\end{array}$ & $\begin{array}{c}0.001 \\
(0.079)\end{array}$ \\
\hline$\overline{\mathrm{R}}^{2}$ & .686 & .171 & .746 & .013 \\
\hline$F$ & 30.96 & 1.98 & 15.72 & 1.05 \\
\hline S.E.E. & 0.434 & 0.219 & 0.616 & 0.134 \\
\hline
\end{tabular}


TABLE IV

Regression Coefficients for the Randomly Selected County Sample

\begin{tabular}{|c|c|c|c|c|}
\hline \multirow[b]{2}{*}{ Variable } & \multirow[b]{2}{*}{ Total } & \multicolumn{2}{|c|}{ Regression } & \multirow[b]{2}{*}{ Large City } \\
\hline & & Small City & Medium City & \\
\hline$\alpha$ & $\begin{array}{l}1.409 \\
(3.969)^{\mathrm{a}}\end{array}$ & $\begin{array}{l}1.313 \\
(2.080)^{\mathrm{a}}\end{array}$ & $\begin{array}{l}-0.369 \\
(0.606)\end{array}$ & $\begin{array}{c}0.435 \\
(0.718)\end{array}$ \\
\hline $\mathrm{F}_{\mathrm{f}}$ & $\begin{array}{l}0.071 \\
(1.669)^{b}\end{array}$ & $\begin{array}{l}-0.019 \\
(0.228)\end{array}$ & $\begin{array}{l}0.050 \\
(0.908)\end{array}$ & $\begin{array}{c}0.044 \\
(0.684)\end{array}$ \\
\hline SR & $\begin{array}{c}0.043 \\
(10.005)^{\mathrm{a}}\end{array}$ & $\begin{array}{l}-0.065 \\
(0.469)\end{array}$ & $\begin{array}{l}-0.093 \\
(0.515)\end{array}$ & $\begin{array}{c}0.504 \\
(15.214)^{\mathrm{a}}\end{array}$ \\
\hline $\mathrm{D}$ & $\begin{array}{l}-0.001 \\
(0.732)\end{array}$ & $\begin{array}{c}0.004 \\
(1.252)\end{array}$ & $\begin{array}{l}-0.003 \\
(1.563)^{\mathrm{a}}\end{array}$ & $\begin{array}{c}0.002 \\
(0.679)\end{array}$ \\
\hline $\mathrm{N}_{\mathrm{GC}}$ & $\begin{array}{l}-0.129 \\
(1.435)^{\mathrm{a}}\end{array}$ & $\begin{array}{c}0.042 \\
(0.360)\end{array}$ & $\begin{array}{l}-0.016 \\
(0.104)\end{array}$ & $\begin{array}{c}0.589 \\
(2.199)^{\mathrm{a}}\end{array}$ \\
\hline $\mathrm{M}_{\mathrm{GC}}$ & $\begin{array}{c}0.109 \\
(0.547)\end{array}$ & $\begin{array}{l}-0.109 \\
(0.309)\end{array}$ & $\begin{array}{c}0.265 \\
(0.964)\end{array}$ & $\begin{array}{l}-0.192 \\
(0.456)\end{array}$ \\
\hline $\mathrm{A}_{\mathrm{GC}}$ & $\begin{array}{r}0.005 \\
(0.884)\end{array}$ & $\begin{array}{c}0.004 \\
(1.505)\end{array}$ & $\begin{array}{c}0.001 \\
(0.905)\end{array}$ & $\begin{array}{c}0.002 \\
(1.524)\end{array}$ \\
\hline $\mathrm{E}_{\mathrm{GC}}$ & $\begin{array}{l}-0.056 \\
(1.776)^{\mathrm{a}}\end{array}$ & $\begin{array}{l}-0.049 \\
(1.032)\end{array}$ & $\begin{array}{c}0.049 \\
(1.150)\end{array}$ & $\begin{array}{l}-0.022 \\
(0.489)\end{array}$ \\
\hline $\mathrm{P}_{\mathrm{GC}}$ & $\begin{array}{l}-0.168 \\
(3.122)^{\mathrm{a}}\end{array}$ & $\begin{array}{l}-0.170 \\
(2.188)^{\mathrm{a}}\end{array}$ & $\begin{array}{c}1.424 \\
(2.512)^{\mathrm{a}}\end{array}$ & $\begin{array}{l}-0.453 \\
(1.901)^{\mathrm{a}}\end{array}$ \\
\hline $\mathrm{Y}_{\mathrm{GC}}$ & $\begin{array}{c}0.113 \\
(1.254)\end{array}$ & $\begin{array}{c}0.299 \\
(1.289)\end{array}$ & $\begin{array}{l}0.589 \\
(2.143)^{\mathrm{a}}\end{array}$ & $\begin{array}{c}0.492 \\
(1.876)^{\mathrm{a}}\end{array}$ \\
\hline $\mathrm{NKE}_{\mathrm{GC}}$ & $\begin{array}{l}-0.00000003 \\
(0.551)\end{array}$ & $\begin{array}{l}-0.00002 \\
(2.877)^{\mathrm{a}}\end{array}$ & $\begin{array}{l}0.0000008 \\
(0.523)\end{array}$ & $\begin{array}{l}-0.00000003 \\
(0.733)\end{array}$ \\
\hline $\mathrm{NE}_{\mathrm{GC}}$ & $\begin{array}{c}0.116 \\
(0.894)\end{array}$ & $\begin{array}{l}-0.074 \\
(0.405)\end{array}$ & $\begin{array}{l}0.009 \\
(0.042)\end{array}$ & $\begin{array}{l}-0.103 \\
(0.331)\end{array}$ \\
\hline $\mathrm{I}_{\mathrm{GC}}$ & $\begin{array}{l}-0.021 \\
(2.717)^{\mathrm{b}}\end{array}$ & $\begin{array}{l}-0.018 \\
(1.079)\end{array}$ & $\begin{array}{l}0.011 \\
(1.137)\end{array}$ & $\begin{array}{l}-0.012 \\
(1.006)\end{array}$ \\
\hline$\overline{\mathrm{R}}^{2}$ & .400 & .109 & .280 & .841 \\
\hline $\mathrm{F}$ & 10.12 & 1.54 & 2.98 & 22.63 \\
\hline S.E.E. & 0.259 & 0.251 & 0.198 & 0.191 \\
\hline
\end{tabular}

